\title{
INSTRUÇÃO POPULAR E NAÇÃO LITERÁRIA \\ N'O RECREADOR MINEIRO
}

\section{POPULAR EDUCATION AND LITERARY NATION \\ IN THE RECREADOR MINEIRO}

Maria Francelina Ibrahim Drummond*

RESUMO: O artigo comenta a revista literária O Recreador Mineiro (1845-48) e a proposta editorial de instrução pública através da Literatura.

PALAVRAS-CHAVE: romantismo, instrução, leitor.

ABSTRACT: This article analizes the first review O Recreador Mineiro (1845-48) and the publishing plan of popular education through Literature.

KEY WORDS: Brazilian Romantic movement, education, reader.

* Doutora em Literatura Comparada (UFMG), Professora Visitante da 



\section{INSTRUÇÃO POPULAR E NAÇÃO LITERÁRIA N'O RECREADOR MINEIRO}

\section{Cidade e vida moderna}

No poema Dilúvio de papel, de Bernardo Guimarães, o poeta-jornalista sente-se atordoado pela imensa quantidade de impressos que o século XIX produzia - “já o globo se amortalha em camadas de papel”. São jornais, principalmente jornais, de todos os tamanhos, tendências e opiniões, efêmeros uns, mais duráveis outros, volantes, ágeis que atropelam a vida do poeta no escritório, na rua, dentro de casa, voando para todos os lados, multiplicando-se aos milhares. Numa visão fantástica, esse atordoamento resultara de maldição da Musa clássica contra o poeta que, abandonando a lira, tornarase jornalista e também responsável, portanto, pela reprodução infinita dos jornais.

Essa velocidade hiperbólica com que o poema caracteriza a vida urbana da época - e que roubava o sossego ao poeta -, tem o mesmo quê moderno da mensagem da revista literária $O$ Recreador Mineiro, publicada em Ouro Preto em 1845. Atenta à beleza particular, à beleza da circunstância e à pintura dos costumes, a revista influencia a cidade na modernização ainda tímida de seu cotidiano. Bens de consumo da época - circo, teatro, cinerama, a moda, armazéns de variedades, lojas femininas de fazendas finas e perfumes, objetos e signos modernos que vinham da Corte e do estrangeiro - já se tinham instalado na vida da cidade. E, no mesmo ano de 1845 , chegava a Ouro Preto o daguerreótipo, processo fantástico de reproduzir o mundo dos objetos com fidelidade nunca antes imaginada. A fotografia captava o 
fugaz e o instantâneo, a cena corriqueira e a solenidade dos acontecimentos. Simbolicamente, a fotografia democratizava a duplicação da realidade. O presente se impunha, e a Musa antiga estava, de fato, destronada:

Esse ofício que ensinas já não presta.

Vai tocar tua lira em outras partes

Que aqui nestas paragens só tem voga

Comércio, indústria e artes. ${ }^{1}$

Há o riso irônico do poeta por trás desta visão do dezenove como século de papel, traduzido na desconfiança de que o progresso comercial, a exuberância industrial e a beleza das artes não chegariam igualmente a todos. Também O Recreador Mineiro saúda a modernidade com entusiasmo, mas de modo desconfiado, sob a condição de que a imprensa literária atue como meio de instrução, ou elevação moral e social do leitor, sobretudo aqueles de mórbida compleição e de difícil restabelecimento que a revista denomina os de terceira classe.

O horizonte possível para esse restabelecimento na sociedade pós-colonial, monárquica e escravista era ainda a Literatura, não para transformar a todos em sábios e eruditos (da ilusão ilustrada), mas para dotar cada indivíduo dos meios de empregar, em maior proveito seu e da sociedade, as faculdades que Deus the concedeu.

\section{Tema e horizonte da revista}

O Recreador Mineiro (1845-48) é desconhecido da historiografia literária e sequer mencionado nos estudos sobre publicações congêneres do Rio de Janeiro e de São Paulo no período de transformação romântica na literatura brasileira.

Essa lacuna se deve certamente ao fato de que a imprensa em Minas Gerais no século XIX se destacou como documento de história política, dada a importância que esta Província manteve nos destinos políticos do Império. Enquanto a imprensa política mineira se impôs mais facilmente ao historiador, a imprensa literária não se salientou, ficando a imagem de Minas Gerais vinculada quase exclusivamente ao Arcadismo e, no Romantismo, ao Bernardo Guimarães de A escrava Isaura e O seminarista.

\footnotetext{
${ }^{1}$ Bernardo Guimarães, Dilúvio de papel.
} 
Estudos mais atualizados de cultura impressa ${ }^{2}$ na Província de Minas, sob área de influência de Ouro Preto, sinalizam para outra compreensão da produção literária e das idéias sobre literatura que ali circulavam na primeira metade do século XIX. Sintonizavam a capital de Minas Gerais com a vida intelectual da Corte no Rio de Janeiro, e a vida intelectual em Pernambuco e Bahia; mantinham contato com a incipiente São Paulo, através da Faculdade de Direito onde estudantes mineiros se destacaram no jornalismo literário e na crítica, desde a Sociedade Filomática até a geração de 1840-70, que atuou em outras revistas acadêmicas. Tudo isso gerava intercâmbio e promovia difusão cultural, interferindo no ambiente intelectual da Província.

O predomínio da imprensa de viés político em Ouro Preto não inibiu, portanto, a manifestação literária nos periódicos diários e trissemanais, refletindo influências e gerando seu próprio discurso. A princípio, nas décadas de 1820 e 30, a literatura - nos significados que a época lhe dava -, aparece insinuada na quarta página dos jornais que divulgava artigos de crítica, cartas de leitor sobre acontecimentos culturais, anúncios de livros, festas, apresentações de circo e teatro. Este, a partir da década de 40, desprende-se do calendário de solenidades oficiais e passa a revelar a autonomia de grupos e companhias, locais e de fora, com funcionamento intenso.

Em 4 de novembro de 1843, saía o primeiro periódico propriamente literário de Minas, $O$ Athenêo Popular que, redigido pelo padre liberal Antônio de Sousa Braga, difundia o conceito de literatura equivalente, ao mesmo tempo, a atividade de irradiação das luzes científicas e espaço da especulação filosófica. Tinha feição pré-romântica, herdada do neoclassicismo, e resquícios ilustrados que se revelavam com maior clareza na função moralizadora e civilizadora atribuída à literatura e no predomínio do pensamento crítico reformador sobre as criações poéticas. Donde, portanto, o texto compacto, reflexivo, circunspecto e mesmo inacessível ao leitor comum. No entanto, em 1845, a experiência do padre liberal se superaria, abrindo, de fato, o discurso literário aos domínios da modernidade na revista $O$ Recreador Mineiro, contemporânea da Minerva Brasiliense (184345) e antecessora de Guanabara (1850-55), publicações que marcaram o amadurecimento crítico da atividade literária brasileira.

\footnotetext{
${ }^{2}$ A expressão designa as sociedades dotadas de condições econômicas e culturais de produzir livros, periódicos e outros impressos.
} 
Sinal da vitalidade na imprensa ouro-pretana, O Recreador Mineiro foi resultado da originalidade do impressor Bernardo Xavier Pinto de Sousa e das condições históricas e sociais que Ouro Preto oferecia à arte tipográfica. Como se sabe, já em 1807, na ainda Vila Rica, Padre Joaquim Viegas de Menezes ${ }^{3}$ imprimia aquele que pode ser, de fato, considerado o primeiro livro feito na Colônia, o Canto Encomiástico, de Diogo de Vasconcelos. Até final do século, apesar de outros centros urbanos com imprensa pujante, como Diamantina, Serro e São João del Rei, Ouro Preto concentrou a editoração em Minas Gerais, em volume, variedade de títulos e influência na formação do público, devendo-se isso em parte à atuação de impressores e gravadores eminentes que a antiga capital atraía. Entre os nomes vinculados à da imprensa do período, está Bernardo Xavier Pinto de Sousa, personalidade ilustre no ambiente cultural daquela cidade, que ali desempenhou atividades de livreiro, impressor, redator ${ }^{4}$, tradutor de matérias do francês, inglês e alemão publicadas na revista, nas décadas de 1840 e 1850. Teve atuação destacada na divulgação da literatura e formação do leitor da Província de Minas com as publicações de sua oficina, a Typographia Imparcial, situada à antiga Rua do Jiló, no 9. Herman Burmeister, em passagem por Ouro Preto em 1850 , observou a livraria em detalhes preciosos. Ela funcionava noutro endereço, separada da tipografia, coisa pouco comum àquela época:

A casa do lado direito da ponte, em frente à Contadoria, é a livraria de Bernardo Pinto de Sousa cujo estoque é, em sua maioria, integrado por trabalhos de edição própria. Comprei ali uma gramática portuguesa para uso escolar e folheei vários livros, entre os quais quero citar os seguintes, apenas para dar uma idéia dos assuntos que interessam aí: uma descrição da cidade de Jerusalém; uma coleção de novelas portuguesas em oito volumes que muito me interessaram; um livro elementar para crianças sobre 'omni scibilli' com gravuras da mitolo-

\footnotetext{
${ }^{3}$ Natural de Ouro Preto, este impressor, pintor e gravador teve atuação eminente na Régia Oficina Tipográfica do Arco do Cego em Lisboa entre 1797 e 1801, ao tempo em que outro brasileiro ilustre, Frei Manoel da Conceição Veloso, dirigia aquele centro de arte tipográfica. Volta para Minas em 1802 e passa a elaborar prelos e projetos gráficos na capital da Capitania, que deram início à imprensa mineira.

${ }^{4}$ O Recreador Mineiro foi um dos documentos de Minas levados à Exposição do Rio de Janeiro de 1881 em cujo catálogo ficou assim identificado: "Este periódico teve por fundador e principal redator a Bernardo Xavier Pinto de Sousa." (CATÁLOGO, p. 442).
} 
gia grega e da história natural, e ainda vários outros livros escolares para cursos ginasiais. (BURMEISTER, p. 231)

A livraria não só vendia como também emprestava livros e os cedia por assinatura aos freqüentadores do Gabinete de Leitura da cidade, como se lê no anúncio publicado n'O Conciliador de 6 de janeiro de 1851:

Tendo-se acabado o gabinete de leitura roga-se a prompta entrega de todos os livros que por assignatura ou por emprestimo tem sido levados da livraria de Bernardo Xavier Pinto de Sousa.

Tudo indica que essa livraria tenha fechado as portas no ano seguinte à visita de Hermann Burmeister, pois Bernardo Xavier anunciava em 25 de setembro de 1851, também n' $O$ Conciliador, uma extensa lista de livros à venda. Obras de Voltaire, Molière, Racine, Beaumarchais, Gonçalves Dias, Antônio José, além das referidas pelo título: Avarento, Doente Imaginário, Casamento do Fígaro, Alzira, Tancredo, Fedra, Leonor de Mendonça, Guerras de Alecrim e Mangerona, Radamisto, Andrômaca, Tartufo, Nova Castro eram os remanescentes de seu precioso estoque.

Em $1^{\circ}$ de janeiro de 1848, um longo escólio à moda de resposta - comum em debates e entreveros que alimentaram a imprensa do século XIX - mostra sinais de crise, não financeira, mas de idéias. Sugere descontentamento do editor com as críticas vinha recebendo em relação à sua conduta editorial e mostra divergências na opinião pública. A revista continua referindo-se ao leitor, que foi seu alvo e seu contraponto durante todo o tempo da publicação. Finaliza, dizendo:

Os R.R. (redatores)concluem este artigo fazendo ardentes votos para que a sua Empresa possa encerrar a expressão de sua grata memoria para com o Publico Mineiro; e qualquer que seja o destino de seus escriptos, os R.R. felicitão-se com a duração deste solemne testemunho de seus sentimentos. (RM, p. 1106)

Mas, em 15 de junho daquele ano, sem maiores comentários e outras explicações, uma coluna à ultima página é breve ao declarar:

Termina com este numero a publicação do Recreador Mineiro. Ao despedirnos dos nossos assignantes, cumprimos um grato dever agradecendo-lhes o 
apoio que nos prestarão, maxime aquelles que, dedicados à nossa empreza, constantes em sua protecção, nos acompanharão desde $o 1^{\circ}$ até $o$ ultimo numero.

Opportunamente distribuiremos por estes srs. o indice geral das materias que compoem os 7 tomos do Recreador Mineiro.

Os srs. assignantes que se achão em debito são rogados a mandar saldar as suas contas, poupando-nos assim ao trabalho de outros avisos, annuncios e mais diligencias a tal respeito. Indemnisaremos os srs. assignantes de qualquer numero que se extraviasse.

Bernardo Xavier Pinto de Sousa fecha O Recreador Mineiro, mas ainda continuou em meio à lida intelectual de Ouro Preto, como livreiro e homem dedicado aos livros. Em 1846, extinta a Sociedade Promotora da Instrução Pública, encarregada de cuidar a biblioteca pública da cidade, criada em 1831, ele se oferecia para guardar, em sua própria casa, o acervo então abandonado nas dependências do Palácio. ${ }^{5} \mathrm{O}$ Presidente da Província fez constar no Relatório do Governo daquele ano:

Tomando conta da administração da Província, achei estes livros, entre os quais se vêm muitas obras interessantes, atirados na capela do Palácio do Governo e servindo de pasto às traças e estragando-se completamente.

Não querendo que eles se perdessem de todo mandei-os transferir para a casa do cidadão Bernardo Xavier Pinto de Sousa, que se obrigou gratuitamente a têlos em boa guarda, conservá-los e mesmo franquear sua leitura, com as devidas cautelas, a quem os precisasse. (RELATÓRIO, p. 78).

Além da coleção completa d'O Recreador Mineiro, o rol das publicações feitas na Typographia Imparcial inclui o Almanack dos eleitores da Província de Minas Gerais, com quadros estatísticos e dois mapas gerais, de 1845, História da revolução de Minas em 1842, redigida e compilada por Bernardo Xavier; os jornais Boletim Official (1845-48), O Constitucional (1846-47), O Povo (1849-40); as Falas do Governo à Assembléia Legislativa e os respectivos Relatórios provinciais nos anos de 1845, 1846, 1847, 1848 e 1849.

${ }^{5}$ Em 1851, o acervo passava a ocupar salas do Palácio. Mais tarde, a biblioteca pública voltava a ter sede própria. Em 18 de março de 1859 o Correio Official anunciava que ela estava adequadamente instalada, em pleno funcionamento, inclusive aos domingos e dias santos, nos horários diurno e noturno, para facilitar a todos o acesso aos livros. 
A livraria parece ter sido o derradeiro empreendimento de Bernardo Xavier na capital de Minas de onde se transferiu por volta de 1852 . Em 1853, está estabelecido no Rio de Janeiro onde ocupa o cargo de oficial da administração central da estrada de ferro Pedro II, é major reformado da Guarda Nacional, proprietário de empresa de loterias, tipografia e livraria à Rua dos Ciganos onde José de Alencar, mais tarde, encontraria muitos exemplares do seu O guarani à venda ${ }^{6}$.

Foram publicados oitenta e quatro números de O Recreador Mineiro, num total de 16 páginas cada edição, tamanho $14 \times 20$, circulação quinzenal, formando doze edições semestrais que corresponderam a um tomo. O conjunto da revista perfez sete tomos, com numeração contínua para encadernação, no formato de livro. Circulou ininterruptamente três anos e meio, em diferentes províncias; tinha correspondente em Lisboa e Paris; sobrevivia de vendas avulsas e assinaturas, sem publicidade ${ }^{7}$. As matérias publicadas encaixavam-se nas três grandes secções Memória, Razão e Imaginação, com o objetivo amplo de formar o leitor nas Luzes da Instrução, pois "são as letras o alimento do espírito".

Tendo em vista esse objetivo, O Recrador Mineiro identificou no leitor, na leitura e recepção os alvos preferenciais em torno dos quais desenvolveu a sua proposta editorial. Tudo indica que teve sucesso e repercussão pública, haja vista que, em janeiro de 1846, com um ano de circulação, contava com 723 assinantes em Minas Gerais, Rio de Janeiro, São Paulo e Espírito Santo além das vendas avulsas. Correspondia com periódicos importantes, O Carapuceiro, do Recife, Museu Universal e Ostensor Brasileiro, do Rio de Janeiro.

O Recreador Mineiro apresentava novidades modernas ao leitor àquela altura do século XIX, falando ao homem urbano e reconhecendo a divisão entre vida pública e vida privada estabelecida pelos novos tempos. A cidade se revela aos poucos nas páginas da revista. O programa editorial supera o discurso neoclássico que era a tendência ainda predominante enquanto inspiração literária; defende ardorosamente o romance como gênero democrático que não só populariza as letras, mas dá acesso

\footnotetext{
${ }^{6}$ José de Alencar, Como e porque sou romancista, p. 62.

${ }^{7}$ Para atender a reivindicação dos leitores e manter a integridade do programa literário proposto na revista, a partir de 1 de setembro de 1845, o editor manteve outra folha, o Correspondente, que acolhia anúncios, comunicados e outras matérias pagas. A criação desse jornal indica a popularidade que a Revista já tinha então alcançado.
} 
ao verdadeiro conhecimento da realidade social e política de um país; bate-se pela tradução para que o acesso a obras literárias estrangeiras se popularize; difunde o folhetim romântico já no primeiro número, a crítica, as narrativas de viagem, poesia popular e modinha, entre outras formas literárias e outros gêneros comandados pela imaginação; defende e deseja a sociedade do trabalho livre, sinal emancipador sob o escravismo. Ao fazer a passagem do Neoclassicismo para o Romantismo, $O$ Recreador Mineiro tornava-se porta-voz do moderno e da modernidade e espécie de divisor de águas nas Letras da Província de Minas.

Por essa filiação ao pensamento romântico, a revista via na instrução pública e popular um dos caminhos para a construção da Nação brasileira - e também, por conseqüência, da Nação Literária. Para isto, já no primeiro número, $O$ Recreador Mineiro insistia na identificação do perfil de seus leitores, com vistas a criar estratégias adequadas a conquistá-los para a leitura literária. Deixa subentendido que essa leitura deve ser uma prática deleitável sempre e prática formadora idealmente. Seu texto não tem, por isso, um sentido único de moralizar, mas um sentido múltiplo de entreter para instruir. Ou seja, recrear deleitando:

Por conseguinte, determinado em virtude de tão sólidas bases o sistema de nossa redação, O Recreador Mineiro convence-se da necessidade de seus passos não só pelos domínios da literatura e das ciências, como também pelas regiões do jocosério e da hilaridade. (RM, p. 7)

Instrução, povo e nação mantêm um estreito vínculo que forma um dos eixos temáticos d' O Recreador Mineiro. Quatro artigos de fundo - Contextura de um periódico popular; Instrução popular; O romance e Traduções - demonstram a circularidade dessas idéias românticas e definem o percurso da revista, no ideal de atingir três categorias de leitor caracterizadas com precisão:

Primeira classe: a dos que procuram unicamente as luzes da instrução, considerada em si só. Segunda: a [classe] dos que amam a instrução recreando-se. Terceira: a [classe] dos que buscam na leitura um passatempo contra o tédio que os domina, e que só se agradam de matérias frívolas. (RM, p. 7) 
A primeira classe era restrita; a segunda, mais numerosa e a terceira, "de mórbida compleição e difícil restabelecimento" e, por isso, digna da atenção especial da revista. Como se observa, o redator foge de duas posições extremadas sobre a realidade do país no século XIX, a que mostrava um Brasil absolutamente sem leitores e a que dava a ilusão de que todos liam. ${ }^{8} \mathrm{~A}$ instrução popular defendida n' O Recreador Mineiro tem, portanto, o sentido de atingir especialmente a terceira classe de leitores, que forma a grande massa do público. Essa perspectiva é, de fato, assumida no projeto humanista de Bernardo Xavier Pinto de Sousa, haja vista a apreciação crítica que ele faz do romance, numa época em que o gênero ainda era alvo de controvérsia, pouco reconhecimento e restrição moralista, sobretudo do leitor grave':

O romance, considerado como futilidade por algumas pessoas graves, mas cuja falta de bom gosto por isso mesmo se denuncia, é entretanto o resumo dos hábitos e costumes de uma nação.

Opõe narrativa romanesca - livre e comandada pela imaginação, e narrativa histórica, destinada à crônica da aristocracia. Opõe escritor e historiador, mostrando que o primeiro leva à realidade próxima e vivenciada pelo homem comum; o historiador, ao contrário, deforma o real porque apenas mostra as classes dominantes. Inverte, então, a perspectiva convencional: o relato do historiador não é confiável como fonte da História, mas sim, o romance que capta, de verdade, a realidade nua e crua porque entra na choupana do pobre, entende o drama da rua, conversa com todos e capta, enfim, o pulsar da vida de um povo:

Quantas vezes o filósofo imparcial embalde busca a verdade na história, e vai encontrá-la no romance? Mil vezes o historiador traça a seu jeito os fatos, dá-lhes outra aparência. Orna-os de outras molduras, enquanto que o romancista, parecendo entregue todo à imaginação, descreve fielmente os costumes da época, e apresenta em seus quadros as virtudes e os vícios do seu tempo e

\footnotetext{
${ }^{8}$ Romances urbanos que fazem representações do mundo da leitura criam geralmente a ilusão de que todos no Brasil liam e que o livro era objeto indispensável à vida cotidiana. Ao contrário, em narrativas que ficcionalizam realidades regionais, mesmo sob a perspectiva romântica, raramente há cenas de leitura e presença do livro.

${ }^{9}$ Brás Cubas falaria, ao final da década de 1860, do lugar precário do romance, oscilando ainda entre o leitor grave e o leitor frívolo.
} 
povo, e, deleitando, mais propende à verdade do que a chamada História. A história com todos os fumos de antiga aristocracia, apenas demora suas vistas soberanas sobre altos casos, os reis, suas vitórias, desastres e política; o romance, menos altivo, democrata moderno, compraz-se com poucas coisas, abraça a multidão, identifica-se com o povo, e modesto segue a índole e caráter nacional. (RM, p. 9).

O artigo intitulado Traducções apresenta discussão importante no contexto das idéias sobre instrução popular e acesso à literatura. É muito evidente que se trata, em primeiro lugar, de uma resposta do redator sobre o preconceito contra a tradução de obras literárias. Ele disfere farpas ao intelectual brasileiro que satiriza e menospreza o trabalho do tradutor, recusando-lhe o mérito sob a presunção de que a tradução falseia a obra original. Alega, para isso, questões de razão, utilidade pública e justiça como justificativas do ofício do tradutor. A tradução garantia o acesso do leitor comum a riqueza de outras literaturas, opinião partilhada com Madame de Staël, que o redator cita, frisando a importância coletiva da difusão de obras literárias:

(...) nenhum serviço mais eminente se podia atribuir à Literatura do que transferir de uma língua estrangeira para o próprio idioma as obras-primas do engenho humano. Cada uma das nações modernas jamais passaria da indigência se existisse reduzida à sua própria riqueza. (RM, p. 65)

O discurso d' O Recreador Mineiro é inflamado sem resvalar no panfleto; é contido o bastante para não causar repulsa dos segmentos dominantes e transitar nos diversos estratos da opinião pública como um produto posto à venda. Tudo indica que o redator é consciente dessa realidade moderna, o que não invalida de maneira nenhuma a defesa de seus ideais de instrução popular e nação literária. Não há, como se poderia esperar, discussão específica sobre literatura brasileira nas páginas do Recreador. À divulgação de poetas nacionais - Cláudio, Salomé Queiroga, Gonçalves de Magalhães, Padre Silvério Ribeiro, sátiras do Carapuceiro ${ }^{10}$ e outros - somam-se assuntos sobre o Brasil e especialmente Minas Gerais, tratados na secção Memória/História, e que contemplam geografia, corografia, história, mineração,

\footnotetext{
${ }^{10}$ É provável que Bernardo Guimarães tenha sido colaborador da revista, muito jovem ainda, entre os anos de 1845 e 46 quando, ainda em Ouro Preto, se preparava para ingressar na Faculdade de Direito em São Paulo.
} 
hidrografia, biografias, relatos de viajantes, como o de Saint-Hilaire, lançado no Recreador na primeira tradução para a Língua Portuguesa.

Compreendendo não só o que interessa à razão como o que surpreende a imaginação (RM, p. 139), a primeira revista literária de Minas Gerais terá cumprido tarefa que se propôs. Fomentou a reflexão sobre o destinatário do fazer literário e a leitura como direito que o século de papel negou a muitos homens.

\section{Referências Bibliográficas}

ALENCAR, José de. Como e porque sou romancista. Campinas: Pontes, 2005.

BAUDELAIRE, C. O pintor da vida moderna. In: Obra completa. Rio de Janeiro: Nova Aguilar, 1995.

BLAKE, A. Sacramento. Dicionário bibliográfico brasileiro. Rio de Janeiro: Imprensa Nacional, 1900, $7 \mathrm{v}$.

BURMEISTER, Hermann. Viagem ao Brasil. São Paulo: Edusp; Belo Horizonte: Itatiaia, 1980 (Reconquista do Brasil, 23).

CATÁLOGO da exposição de história do Brasil. (1881). Edição fac-similar. Introd. José Honório Rodrigues. Brasília:EdUnB, 1981, 3 v. (Temas brasileiros, 10).

DRUMMOND, Francelina. O Recreador Mineiro: rastros do leitor e da leitura na primeira revista literária de Minas Gerais. UFMG/Letras, 1994 (dissert., digit).

GARMES, Hélder. O romantismo paulista: os Ensaios Literários e o periodismo acadêmico de 1833 a 1860. São Paulo: Alamdeda, 2006.

GUIMARÃES, Bernardo. Poesia completa. Org., introd., cron., e notas de Alphonsus de Guimaraens Filho. Rio de Janeiro: MEC/INL, 1959.

Periódicos:

Jornal da Sociedade Promotora da Instrução Pública, 1831-32.

O Atheneo Popular, 1843.

O Recreador Mineiro, 1845-48.

O Conciliador, 1851.

Relatório do Governo Provincial, 1846.

Recebido em 25 de novembro de 2007

Aceito em 27 de fevereiro de 2008 